\title{
LA DIVISIÓN TERRITORIAL VALENCIANA: ANTECEDENTES, PROBLEMAS Y POLÍTICA DE LA GENERALITAT
}

\author{
Joan Carles Membrado Tena \\ Departament de Geografia \\ Universitat de València
}

\section{RESUMEN}

La Comunitat Valenciana cuenta con una división territorial oficial en dos niveles, formada por 3 provincias y 542 municipios, que se encuentra muy arraigada en la conciencia de la sociedad valenciana. Sin embargo, con el fin de evitar duplicidades y adelgazar la administración, notables políticos y empresarios abogan hoy por la supresión las competencias de las diputaciones provinciales. Algunos intelectuales valencianistas han denunciado además los inconvenientes de la división territorial valenciana en tres provincias, ya que el hecho que una de las tres (la de València) lleve el nombre de todo el territorio debilita la identidad valenciana, especialmente entre los ciudadanos de las otras dos provincias, y dificulta la vertebración territorial. En este artículo nos referiremos a los antecedentes históricos de la división territorial de València, desde la fundación del reino valenciano en el siglo xiII hasta el establecimiento de la actual división provincial (en la primera mitad del siglo xIx). También presentaremos las principales propuestas de división comarcal del País Valenciano, con sus pros y contras. Finalmente expondremos cuál ha sido la política llevada a cabo por la Generalitat Valenciana en este campo: después de 30 años de vigencia de un Estatut que contempla la división comarcal, no parece que el actual gobierno valenciano tenga el menor interés por abordar esta cuestión, ni parece que esté entre sus prioridades la reforma o supresión de las diputaciones.

Palabras clave: división territorial, Comunitat Valenciana, provincia, comarca.

\section{ABSTRACT}

\section{Valencian Territorial Division: Background, Problems, and Valencian Government's Policy}

The Land of València's official territorial division consists of two levels, including 3 provinces and 542 municipalities respectively. Such division is deep-seated in Valencian society. However, some politicians and employers advocate for abolishing the provincial councils, thus avoiding duplication of tasks and reducing government. Some intellectuals who defend the common Valencian identity have denounced the shortcomings of the territorial division into three provinces, claiming that the fact that one of these (that of València) bears the same name as the whole Valencian territory weakens Valencian identity, especially among the people from the other two provinces, and hinders the territorial cohesion of the land of València. In this article we will discuss the historical background of the territorial division of València, since the foundation of its Kingdom in the 13th century until the establishment of the current provincial division (in the first half of the 19th century). We will also present the main proposals of division of València into comarca units (bigger than municipalities, but smaller than provinces), with their respective pros and cons. Finally we will discuss the policy that the Valencian government has carried out in this field. 30 years after the passing of an Estatut (i.e., the Valencian autonomous constitution) which provides for the division of València into comarca units, the current Valencian Government does not appear to have the slightest interest in implementing such a division, and the reform or abolition of province councils does not seem to be among its priorities either.

Contacto: joan.membrado@uv.es 
Keywords: territorial division, Land of València, province, comarca.

\section{INTRODUCCIÓN}

La actual división oficial en dos niveles, la provincia y el municipio, ha logrado penetrar muy profundamente en la conciencia de la sociedad valenciana. No obstante, ciertos sectores (hasta ahora) minoritarios han denunciado sus inconvenientes y han propuesto alternativas a esta división. Por un lado, señalan que los municipios muestran en muchos casos signos de inadecuación a la realidad presente: deben prestar más servicios, pero la grave despoblación de las comarcas interiores los ha dejado con tan pocos recursos que difícilmente pueden prestarlos. Por otra parte, las provincias han demostrado hasta el momento una ineficacia notable en cuanto a la ordenación racional del territorio: el centripetismo que ejercen las capitales de provincia tiene como resultado que un 54\% de la población valenciana resida en las áreas urbanas de las tres capitales, que no suponen más del 6\% del territorio. Este centripetismo se debe a la concentración de los servicios (administrativos, sanitarios, judiciales, educativos, etc.), el comercio y la industria en las capitales de provincia y sus áreas urbanas. No obstante, cabe distinguir entre, por un lado, las áreas urbanas de Castelló y València, que concentran 2/3 de las respectivas poblaciones provinciales, y, por otro, la de Alacant/Alicante (incluyendo Elx/Elche), donde la concentración de población no llega al 40\% (tabla 1). En esta última provincia, la notable industria de sus comarcas interiores (Alto Vinalopó, Vinalopó Mitjà, Alcoià, Foia de Castalla) y el fuerte desarrollo turístico residencial de la Vega Baja y de la Marina han atenuado la macrocefalia de la capital y su área urbana. ${ }^{1}$

Tabla 1. Centripetismo de las capitales de provincias en València (2011)

\begin{tabular}{|c|c|c|c|}
\hline & Área Urbana Integrada $(\mathrm{hb})$ & Provincia $(\mathrm{hb})$ & \% población \\
\hline València & 1.702 .100 & 2.578 .719 & 66 \\
\hline Alacant & 757.683 & 1.934 .127 & 39 \\
\hline Castelló & 376.273 & 604.344 & 62 \\
\hline
\end{tabular}

Fuente: Instituto Nacional de Estadística. Padrón municipal 2011. Elaboración propia.

Existe, además, una mentalidad competitiva entre provincias que lleva a pensar que si la provincia vecina tiene una universidad, un puerto, un aeropuerto o se celebra en ella cualquier gran evento deportivo, también la propia provincia debería tener lo mismo, en lugar de considerar que su comunidad ya dispone de estas instalaciones u oportunidades y aprovecharse de ellas.

Además, las provincias dificultan la vertebración de la comunidad autónoma valenciana, ya que fomentan un sentimiento de pertenencia e identidad estrictamente provinciales en sus habitantes, que en este territorio resulta particularmente difícil de compatibilizar con un sentimiento de pertenencia a un todo identitario valenciano, dado que la provincia central recibió desde su creación el nombre del antiguo reino común, es decir, València. La oposición castellonense/valenciano/alicantino que resulta de la división provincial de Javier de Burgos de 1833 tiende a excluir de la valencianidad a los ciudadanos de las provincias del norte y del sur, mientras que fomenta en los de la del centro el hábito de identificar València y, por tanto, lo valenciano únicamente con su propia provincia.

El resultado de esta desvertebración territorial lo encontramos en las encuestas del CIS, que señalan que el $50 \%$ de los habitantes de la provincia de Castelló y el $45 \%$ de los de la de Alacant se sienten únicamente españoles o más españoles que valencianos, mientras que en la provincia de València este porcentaje se reduce al $18 \%$. No es que los valencianos de las provincias del norte y del sur sean más nacionalistas españoles que los de la provincia central [si así fuera, habría que concluir que eran los más fervientes nacionalistas españoles de todo el estado, por encima de los castellano-leoneses (donde la categoría correspondiente alcanza el 39\%) y los madrileños (39\% también), considerados hoy como

1 Alacant es la cuarta provincia más poblada de España, pero el área urbana de Alacant-Elx ocupa el octavo lugar entre las españolas. 
la quintaesencia del españolismo.]: simplemente ocurre que muchos de los primeros no se reconocen como valencianos, es decir, no se identifican con el gentilicio que durante siglos los ha denominado y distinguido de otros pueblos peninsulares al considerarlo como más propio, o incluso exclusivamente propio, de los habitantes de la provincia central.

Ni siquiera el uso habitual de la lengua que tanto popular como oficialmente se denomina valenciano logra corregir esta tendencia a sentirse desidentificados de lo valenciano en las provincias del norte y del sur: la provincia de Castelló es la que más utiliza el valenciano y la única de las tres donde el uso familiar de esta lengua es mayor a la del castellano, y sin embargo es la que, según el CIS, presenta menor sentimiento de valencianidad. Tal vez si la pregunta fuese ise siente Ud. tanto de la Comunitat Valenciana como de España? en lugar de la actual (¿se siente Ud. tan valenciano como español?) la respuesta de los residentes en las provincias de Castelló y Alacant fuese diferente. ¿Por qué? Porque al redactar el Estatut valenciano se pretendió evitar el problema de la identificación del nombre del reino que es el fundamento histórico de dicha autonomía con el de una sola de sus tres provincias de origen decimonónico mediante la adopción del sintagma Comunitat Valenciana como nombre de la realidad común. ${ }^{2}$ Dicho intento de solución, con todo, no va a la raíz del problema (que es, como hemos señalado, la actual división provincial, vigente desde principios del siglo XIx, del territorio históricamente valenciano), y por lo tanto no puede extrañarnos que no lo resuelva realmente: el problema es que en dicho sintagma es precisamente el adjetivo valenciana el que aporta el componente identitario, y ya hemos visto cómo la división provincial socava las bases de la identificación de la ciudadanía con dicho adjetivo y dicha identidad. Así, en los últimos tiempos entre Vinaròs y Orihuela tanto la mayoría de los medios de comunicación como la de los representantes políticos tienden a evitar usar el histórico gentilicio valenciano, sustituyéndolo por la perífrasis de la Comunitat Valenciana, y cada vez con más frecuencia, tan solo por de la Comunitat, obviando así el controvertido gentilicio.

En los últimos tiempos, y en el contexto de la actual crisis económica, se han sumado a las voces críticas con la institución provincial y partidarias de su supresión algunos políticos españoles de la oposición ${ }^{3}$ (incluyendo el PSPV), ${ }^{4}$ un notable expresidente de España, ${ }^{5}$ e incluso los grandes empresarios valencianos, ${ }^{6}$ que ven en ellas organismos obsoletos e ineficaces y pretenden transferir a los respectivos gobiernos autonómicos (como ya sucede en las comunidades uniprovinciales) los servicios que las diputaciones prestan a los pequeños ayuntamientos, lo que supondría un ahorro de unos 1.000 cargos políticos en toda España. ${ }^{7}$ Sin embargo, el PP, que gobierna actualmente en España y en València, se resiste a suprimir las diputaciones provinciales y, con ellas, el modelo centralista del estado español para el que estas fueron concebidas.

Son bastantes las propuestas presentadas para sustituir, o al menos reformar, el sistema de división territorial actualmente vigente en València. La mayoría de estas propuestas poseen un espíritu más reformista que rupturista, ya que están diseñadas - por pragmatismo político- para convivir con las provincias, y postulan la necesidad de establecer un nuevo nivel territorial intermedio entre la provincia y el municipio: la comarca. Los defensores de la comarcalización la ven como un instrumento para la descentralización de la administración y los servicios que la Generalitat ofrece a los ciudadanos, para la planificación territorial y también para la canalización del poder democrático, mediante una ley electoral valenciana que tuviera en cuenta criterios de comarcalización, tal como prevé el Estatut valenciano en

\footnotetext{
2 Descartando otras opciones de connotaciones menos neutras y burocráticas, y por eso mismo preferibles en nuestra opinión, como País Valencià o Regne de València.

http://politica.elpais.com/politica/2011/08/16/actualidad/1313510816 868873.html

4 http://politica.elpais.com/politica/2012/12/29/actualidad/1356817214_526811.html

http://elpais.com/diario/2011/02/08/cvalenciana/1297196295 850215.html

6 http://www.levante-emv.com/economia/2011/03/26/empresarios-piden-supresion-diputaciones-fusiones-ayuntamientos/793391.html. Los grandes empresarios valencianos, representandos por AVE (Asociación Valenciana de Empresarios) quieren simplificar la administración mediante fusión de ayuntamientos y eliminación de las diputaciones provinciales, ya que cuatro niveles de administración son excesivos.

7 Para el sociólogo valenciano Rafael Castelló las diputaciones son «una estructura territorial obsoleta [...] que favorece el clientelismo y da poder caciquil a los cuadros intermedios de los partidos, para mantener su control». http://www.levante-emv.com/comunitat-valenciana/2012/08/16/encrucijada-autonomica/928803.html
} 
su artículo 23. ${ }^{8}$ Además la comarca serviría para identificar a sus habitantes con su espacio vivido, lo que se considera como un primer paso para su identificación con el País Valenciano, dado que las comarcas, a diferencia de las provincias, no dan lugar a identidades opuestas o alternativas a la valenciana, al no existir una comarca que se quede con el nombre o el gentilicio comunes. Sorprendentemente, si se piensa en la fuerte identificación de los valencianos de hoy con sus provincias, la idea de comarca ha ido calando también hasta cierto punto en nuestra sociedad. Lugares tan visibles como hospitales, centros educativos, áreas de servicio de autopista, multitud de empresas privadas y algunas denominaciones de origen llevan el nombre de su comarca, y los principales medios de comunicación escritos (Levante-EMV, Las Provincias, Información, etc.) tienen secciones e incluso ediciones comarcales.

En este artículo nos referiremos, en primer lugar, a los antecedentes históricos de la división territorial de València, desde su fundación en el siglo xiı hasta la división provincial del XIx. A continuación mostramos una exposición y crítica de las principales propuestas de división comarcal de València, todas llevadas a cabo durante el siglo XX. Finalmente nos referiremos a la actuación de las instituciones autonómicas valencianas en esta cuestión.

\section{DIVISIONES TERRITORIALES EN LA HISTORIA DE VALÈNCIA}

\subsection{Etapa foral. Gobernaciones, obispados y quarters}

Entre 1232 y 1245 Jaime I fundó el reino cristiano de València, dentro de cuyos límites se incluían la Foia de Castalla y Xixona y la Marina, pero no los territorios colindantes al sur de estos. En el cambio entre los siglos XIII y XIV, su nieto Jaime II incorporó al reino Alacant, Elx, Orihuela y la cuenca del Vinalopó. A partir de ese momento, València quedó dividida administrativamente en dos gobernaciones: la de València o deçà (lo riu de) Xixona, con capital en la ciudad de València (que también era el cap i casal, del reino), y la de Oriola o dellà (lo riu de) Xixona, con capital en Oriola (Orihuela). Debido a sus dimensiones (más de un 85\% de todo el reino), en la gobernación de València se crearon dos subgobernaciones, con capital en Castelló, la del norte (governació dellà lo riu d’Uixó o de la Plana), y en Xàtiva, la del sur (governació dellà lo riu Xúquer). La sotsgovernació dellà Uixó abarcaba un territorio que se extendía desde la frontera con Aragón y Cataluña hasta la Sierra de Espadán y el río d'Uixó o Belcaire. La sotsgovernació dellà Xúquer se extendía entre este río, por el norte, y el de Xixona o Montnegre y las sierras del Maigmó, Castalla y Biar, por el sur (Vid. figura 1).

Por lo que respecta a la gobernación de Oriola, hay que señalar que la frontera sur del Reino de València no quedó definitivamente fijada como se observa en el mapa 1 hasta mediados del siglo XIV. En 1244 se firmó el tratado de Almizra entre Castilla y Aragón, por el que la frontera sur del Reino de València la marcaban las poblaciones de Biar, Castalla y Xixona. Al sur de esta línea, las tierras conquistadas se reservaban a Castilla (mapa 1.1). Décadas después se produjo un conflicto dinástico en Castilla que enfrentó a Sancho IV con Alfonso de la Cerda. Este último ofreció a Jaime II de Aragón el Reino de Murcia a cambio de su apoyo. En 1296 l rey aragonés invadió este reino, pero el cambio de coyuntura en Castilla incitó a Jaime II a someterse a la sentencia arbitral de Torrellas (1304), que se completó con el acuerdo de Elx (1305), por los cuales todo el reino de Murcia, salvo el sector oriental, pasaría a Castilla (Mestre y Sabaté, 1998: 49). Según los nuevos tratados, pasaron al Reino de València la histórica gobernación de Oriola, y también Villena (con Sax), Jumilla, Abanilla y Caudete (Capdet) (mapa 1.2). Medio siglo después, estas últimas se reintegraron a Castilla y se fijó el límite sur del reino valenciano. El Valle de Ayora se incorporó al Reino de Valencia en 1281, y su inclusión fue ratificada en el tratado de Elx de 1305.

La división eclesiástica medieval se adaptaba a grandes rasgos a las gobernaciones y subgobernaciones forales: las del Cap i Casal y Xàtiva formaban parte del obispado de València; la de Castelló, del de Tortosa; y la de Oriola de su diócesis homónima, creada en 1564 (antes había dependido del obispo de Cartagena). Las únicas excepciones eran el Alto Mijares, que formaba parte de la gobernación de la Plana

8 http://www.idpbarcelona.net/docs/normativa/ccaa/normativa/lleis/cvalenciana/estatut.pdf 
Figura 1. División foral del Reino de València

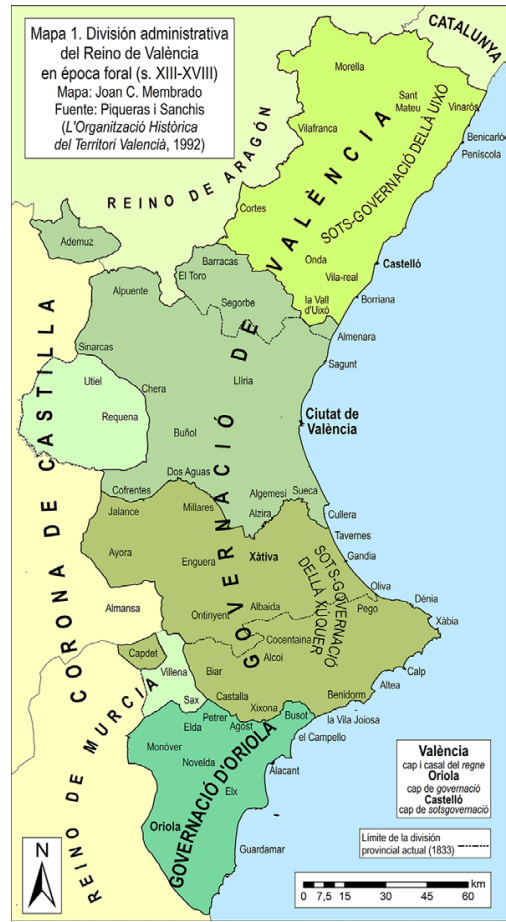

Fuente: Piqueras y Sanchis, 1992, p. 41

pero del obispado de València; y el Alto Palancia y el Alto Turia (incluyendo Ademuz), que pertenecían a la gobernación de València pero al obispado de Segorbe. Además Betxí y Olocau del Rey dependían de Teruel y Zaragoza, respectivamente, y no de Tortosa, y Ayora y Caudete de Oriola y no de València. La reforma de las diócesis de mediados del siglo xx alteró estos límites históricos y los ajustó tanto como pudo a la realidad provincial existente. Sin embargo els Ports y el Baix Maestrat no pasaron a la nueva diócesis llamada de Segorbe-Castelló, sino que continuaron dependiendo del obispo de Tortosa; mientras los valles de Alcoi y la Marina Alta (salvo Calp) no se integraron en Orihuela-Alacant, sino que siguieron bajo la tutela de València.

Figura 1.1 y 1.2. Conflictos territoriales en la frontera sur del Reino de València durante los siglos XIII y XIV.
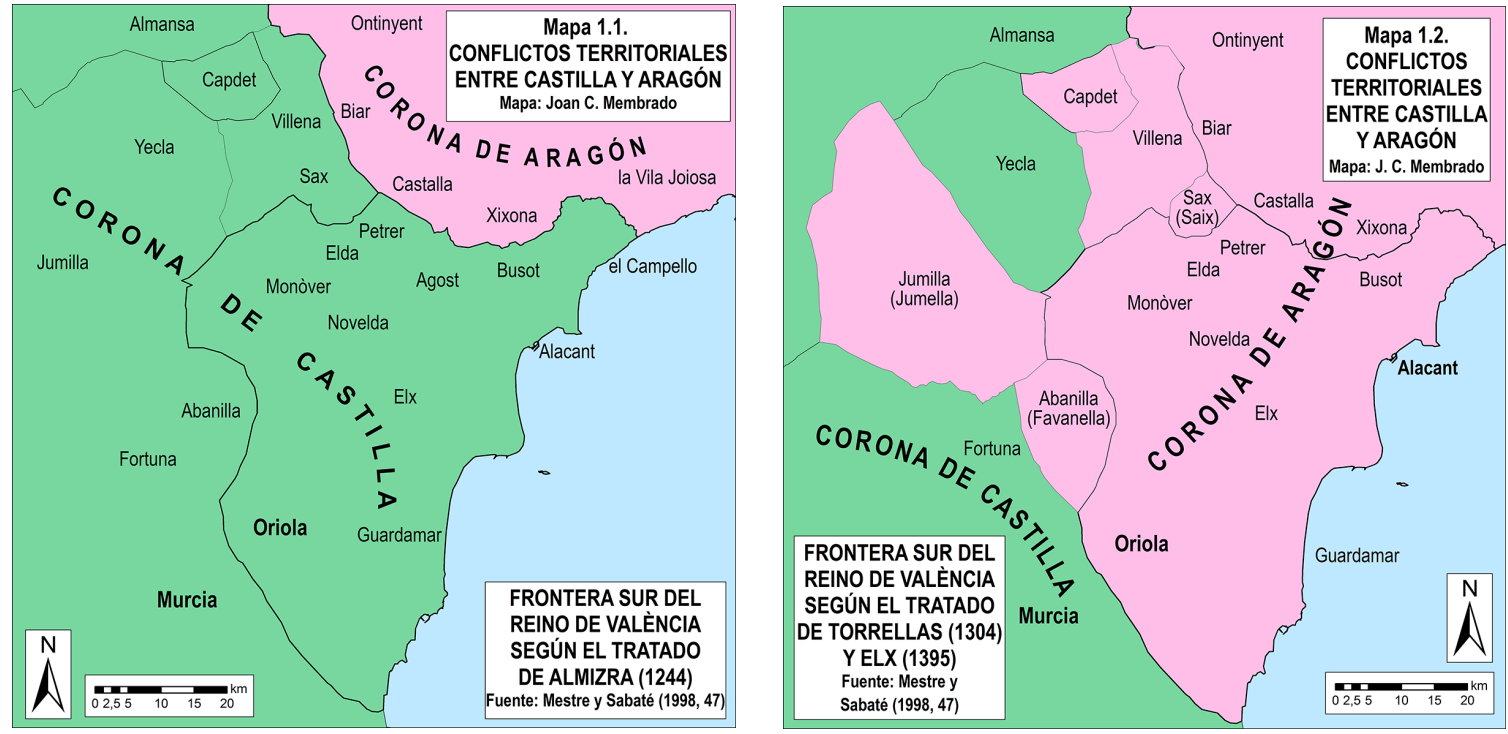

Fuente: Mestre y Sabaté, 1998, p. 47. 
Si nos referimos a divisiones administrativas por debajo de gobernaciones y diócesis, hay que remarcar que una de las primeras divisiones sistemáticas del Reino de València en comarcas, llamadas quarters, es la del llamado tall de drap de 1404, impuesto indirecto de la Generalitat Valenciana sobre el comercio textil, que se recaudaba no de manera centralizada sino a partir de cada quarter. ${ }^{9}$ A pesar de haber transcurrido más de 6 siglos, esta primera división comarcal valenciana es sorprendentemente parecida a la actual. La división territorial moderna incluye 31 comarcas (sin desglosar l'Horta), y la medieval, 26: esta diferencia se debe a que ni Requena ni Villena formaban parte del reino, y a que según el tall de drap el Baix y el Mitjà Vinalopó estaban unidos, como también lo estaban el Alt y el Baix Maestrat, la Marina Alta y Baixa, y la Canal de Navarrés y Xàtiva; en cambio, el Alto Palancia estaba partido en dos, con sus centros en Segorbe y Jérica (figura 2).

Figura 2. Quarters del Reino de València según el Tall de Drap.

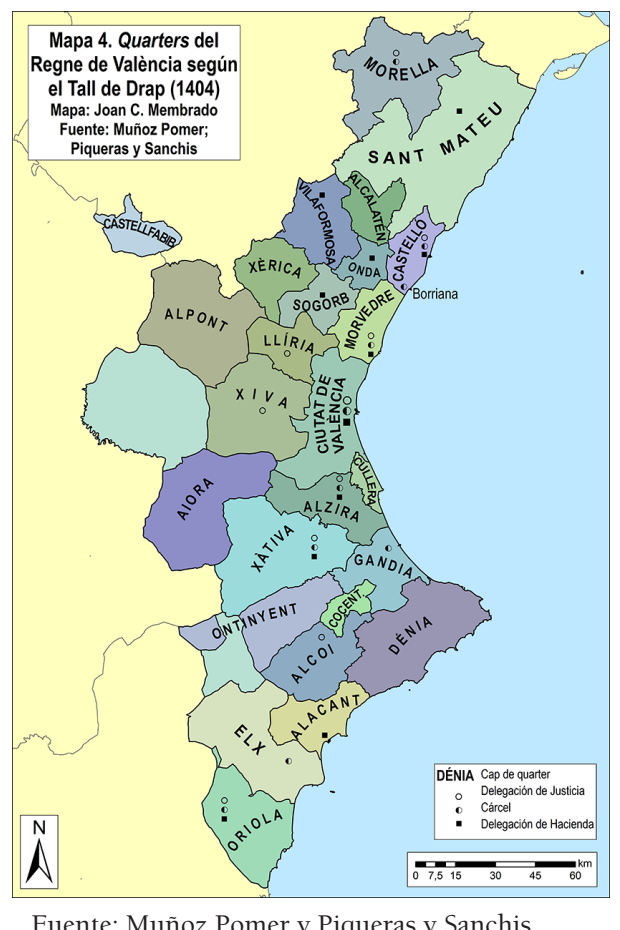

\subsection{Etapa postforal. División provincial. Restricción territorial del topónimo València}

La Guerra de Sucesión acabó de modo favorable a los Borbones, que se consolidaron en el trono hispánico. Con la nueva dinastía se abolieron los fueros valencianos ${ }^{10}$ y el mismo reino de València, y en su territorio se impusieron las leyes de Castilla. También se prohibió el uso oficial y la enseñanza del valenciano. Se produjo asimismo una reforma radical de la división administrativa del antiguo reino valenciano. La nueva división, que pretendía centralizar las Españas e imponer el poder absoluto del estado borbónico frente a cualquier resto de poder foral, fue sin duda, desde el punto de vista de la ordenación del espacio, la más irracional de todas las que se han aplicado en València. El viejo reino, convertido ahora en provincia, se dividió en 13 gobernaciones: en la antigua subgobernación de la Plana se crearon 3, con capitales en Morella, Peníscola y Castelló; en la de València 2, las de València y Alzira; en la subgobernación de Xàtiva se hicieron nada menos que 6, con evidente intención del poder borbónico de castigar y vigilar a los rebeldes setabenses (las capitales fueron Cofrentes, Montesa, San Felipe o Xàtiva, Dénia, Alcoi y Xixona); finalmente, en la

9 Muñoz Pomer, 1985, p. 530-534.

${ }^{10}$ El fuero alfonsino, cuya impronta en la organización territorial de muchos pequeños municipios valencianos fue extraordinaria, también fue abolido en 1707, si bien fue el único fuero valenciano que se recuperó después, en 1772 . Este fuero, promulgado en 1329 por Alfonso el Benigno, es el responsable de la creación de minúsculos municipios alrededor de Orihuela, Cocentaina, Albaida, Dénia, Gandia y Xàtiva (Gil Olcina, 1990, p. 81). 
antigua gobernación oriolana se crearon 2, con capital en Orihuela y Alacant (figura 3). La población valenciana de Capdet (Caudete), que había defendido la causa austracista, pasó desde entonces a formar parte de Murcia (en la actualidad se encuentra en la provincia de Albacete).

Entre la primera división borbónica y el establecimiento de las tres provincias actuales hubo varios intentos de nueva organización del territorio, de efímera vigencia. El primero, promovido por el secretario de hacienda, el mallorquín Miguel Cayetano Soler y Rabassa, tuvo lugar en 1799: se crearon seis nuevas provincias en España, todas marítimas, con el objeto que los pagos a la hacienda real pudieran hacerse más fácilmente, evitando la dilación que suponía viajar a la antigua capital provincial. Una de estas seis provincias fue la de Alacant, que se separó de la de València. Aunque volvió a incorporarse nuevamente en 1805, esta segregación efímera fue un precedente para que luego fuese reconocida de nuevo como provincia (Cebreiro, 2012: 123-126). Pocos años después, en 1810, el rey José I Bonaparte pretendió aplicar en España el modelo de los departamentos franceses, ignorando las realidades históricas y nacionales de los pueblos hispánicos al crear unas prefecturas que mezclaban los territorios valencianos con otros catalanes, aragoneses, castellanos y murcianos.

Al calor de la constitución de Cádiz de 1812, las Cortes encargaron en 1813 una nueva división provincial al cartógrafo y marino mallorquín Felipe Bauzà. Su proyecto dividía España en 44 provincias, entre las cuales se contaba de nuevo la de Alacant. El plan Bauzà jamás se puso en marcha, ya que llegó a las Cortes solo tres días antes de que Fernando VII declarara nula la constitución gaditana (Forcadell y Romeo, 2006: 194).

La segunda división borbónica fue durante el Trienio Liberal, y perdió su vigencia una vez derrocado este gobierno; esta división en provincias, que funcionó durante 1822 y 1823, establecía, a imagen de las antiguas gobernaciones y subgobernaciones forales, cuatro provincias: Castelló, València, Xàtiva y Alacant, aunque los límites de las nuevas provincias no coincidían exactamente con los de las gobernaciones forales. La línea entre la provincia central y la meridional se trasladaba unos $30 \mathrm{~km}$ al norte de la antigua línea Biar-Xixona-Busot, lo que reducía la extensión de la provincia setabense a favor de la de Alacant, que pasaba a ser la nueva capital del sur en detrimento de Orihuela, la cual, junto al resto de la Vega Baja, era incorporada a la provincia de Murcia. El Rincón de Ademuz era separado de València e integrado en Teruel, y en contrapartida algunos municipios aragoneses fronterizos eran incorporados a la provincia de Castelló; el Marquesado de Villena, a la de Alacant; y la Meseta de Requena, a la de València.

Figura 3. División borbónica en gobernaciones (1707-1812). Fuente: Piqueras y Sanchis, 1992

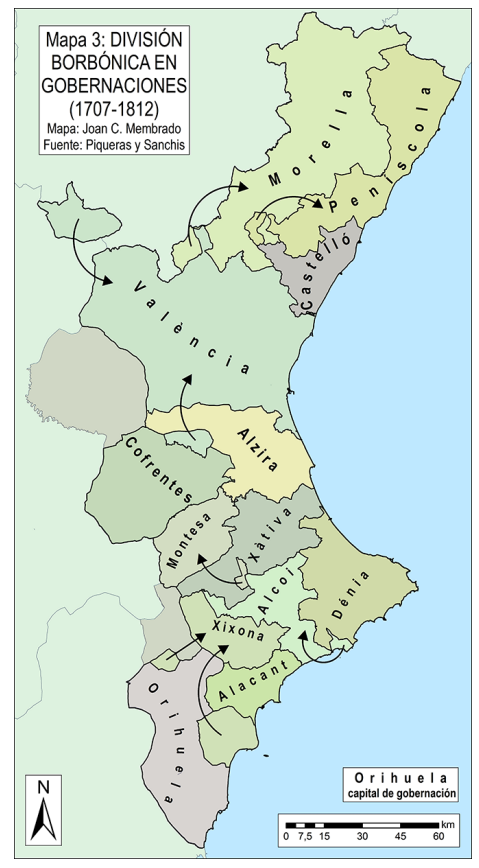


La tercera división borbónica, y actual división provincial de las tierras valencianas, data de 1833, cuando se aprobó la propuesta elaborada por el liberal Javier de Burgos. Esta división restituyó íntegramente los límites históricos del Reino de València, pero pasó por encima de la tradición al partirlo en 3, y no en 4, demarcaciones (provincias): la de Xàtiva fue sacrificada y en su mayor parte incorporada a la provincia de València, y el resto a la de Alacant. Según la primera propuesta de división provincial (1833) la Vall d'Albaida y la Safor (sin la Valldigna) tenían que pertenecer a la provincia de Alacant, pero en 1836 estas comarcas pasaron a la de València, salvo el sur de la Safor (Oliva, Vilallonga y pueblos vecinos) que lo hizo en 1847. Por el norte, hubo un reajuste de los límites provinciales entre las antiguas demarcaciones de Castelló y València al incorporar a la primera la comarca del Alto Palancia (Vid. Figura 4).

La coincidencia inicial de los límites del Reino con la suma de las tres provincias solo duró tres años, debido a dos modificaciones, que tenían ya su precedente en la división del Trienio liberal: en 1836 se añadieron otra vez a la provincia de Alacant las localidades de Villena y Sax, y en 1851 la meseta de Requena volvió a incorporarse a la de València (figura 4). Gátova, incluida en la provincia de Castelló en 1833 sin tener el cuenta que este era el único municipio de dicha provincia situado al sur de la Serra Calderona, pasó en 1995 a la provincia de València.

Entre 1833 y 1982 no hubo pues ningún referente territorial oficial que agrupara el conjunto de los territorios pertenecientes al viejo Reino de València. Joan Fuster comenta que el paso del topónimo València como identificador de todo el territorio al de una sola de sus tres provincias resulta de una malignitat angoixosa ('angustiosa'). Habrá algunos valencianos que ya no serán valencianos, sino castellonenses o alicantinos. Habrá unos valencianos que legalmente serán los valencianos por excelencia y los otros, en consecuencia, tratarán de acentuar su propia denominación territorial. Fuster remarca como en los años 1960 es en la provincia de Castelló donde las vel-leitats provincials son menores, y la ciudad de Alacant donde éstas son mayores. ${ }^{11}$ Para Joan Francesc Mira, la división provincial contribuirá a destruir todavía más la conciencia e identidad valencianas, ya notablemente mermadas desde, al menos, la pérdida de los Fueros (1707). No solo desaparece oficialmente el concepto de (Reino de) València, sino que la inexistencia de un nombre común diferente del de una de las tres provincias tenderá a crear "confusions i distàncies, dobles sentits, reticències $i$, en definitiva, pèrdua de presència del nom identificador de valencians com a igualment propi dels qui han quedat fora de la província de València". Antes de la división provincial "era rigorosament impossible -era impensable-parlar de «valencians», «castellonencs» i «alacantins» com a tres conjunts humans i territorials diferents"; tras la división será "tan freqüent i habitual que arriba a produir «identitats provincials» definides pels límits administratius". ${ }^{12}$ En la actualidad, el topónimo histórico València para referirse a toda la Comunitat es mucho más usado fuera del territorio valenciano que dentro del mismo, ${ }^{13}$ y sobre todo cuando se compara con otras comunidades, lo que evita ambigüedades. ${ }^{14}$

${ }^{11}$ Fuster, 1962, p. 212. Varias décadas después las encuestas del CIS sitúan a Castelló como la provincia con menor grado de valencianidad, no porque en Alacant se identifiquen hoy más que en 1960 con la identidad valenciana, sino porque en Castelló el apego hacia la valencianidad ha descendido desde entonces de manera alarmante.

12 Mira, 1997, p. 192.

13 En la ciudad de Barcelona, una de las principales calles del Eixample, el carrer de València, hace referencia a todo el reino de València, mientras la calle de más abajo (Aragó) se refiere al antiguo reino aragonés y la de más arriba (Mallorca), al antiguo reino de Mallorca o Mallorques.

14 El problema de tener un mismo topónimo (València) para referirse a todo el país, a solo una parte del país (una provincia) y a la capital del país (ciudad) no es muy distinto al que se da en otros territorios. Por ejemplo, en la República Checa, donde para evitar posibles malentendidos sobre el nombre del territorio se ha distinguido en checo moderno entre Cechy (topónimo) - Čech (gentilicio), que significan respectivamente Bohemia-bohemio, y Česká republika / Česko (topónimo) - Český (gentilicio), que significan República Checa / Chequia (es decir, la suma de Bohemia, Moravia y la Silesia) - checo (una persona de cualquiera de estos tres territorios). Otro caso similar es el de México, donde para distinguir la ciudad de México del estado de México y de la federación de estados mexicanos, se han creado tres adjetivos diferentes: mexicano es una persona de cualquier lugar de la federación, mexiquense es alguien del estado de México (que bordea la ciudad de México pero no la incluye), y mexiqueño es alguien de la ciudad de México, aunque a los mexiqueños también se les conoce como capitalinos, defeños (de México DF, es decir del Distrito Federal de México) o, despectivamente, chilangos. En algunos círculos valencianistas minoritarios se propone llamar valentinos a los de la provincia de Valencia y evitar así la confusión con valencianos, que serían de las tres provincias. Otros proponen llamar "provincia central" a la de Valencia. La escasa voluntad política de los partidos mayoritarios hace inviable, por el momento, cualquiera de las fórmulas planteadas para evitar ambigüedades entorno al topónimo València y al gentilicio valenciano. 
Figura 4. División provincial de Javier de Burgos (1833), con sus retoques posteriores (1836, 1847, 1851, 1995).

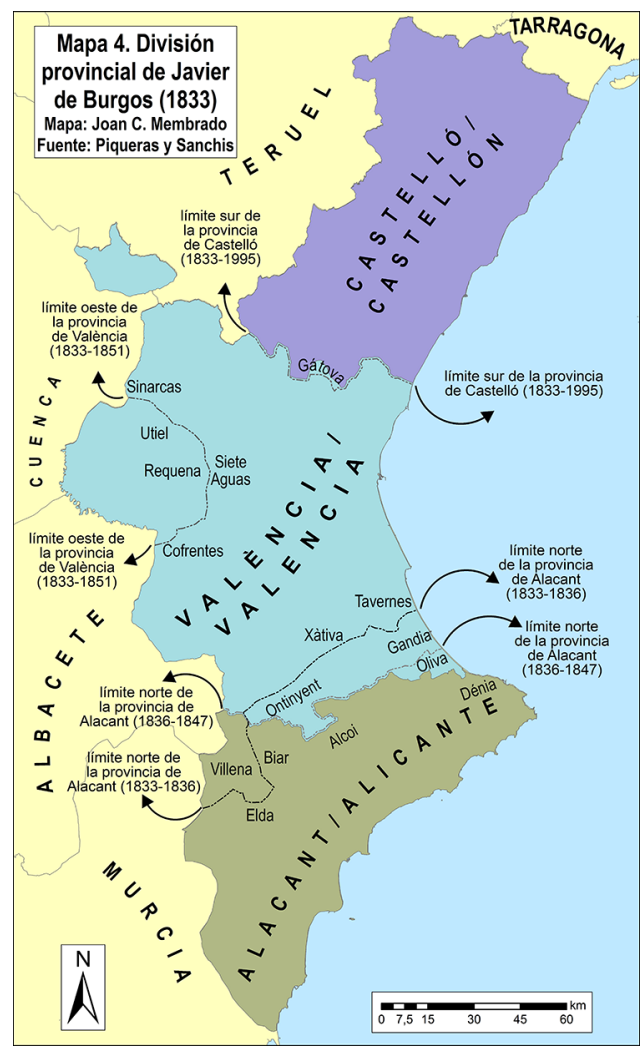

Fuente: Piqueras y Sanchis, 1992. Elaboración propia.

Durante el siglo xx aparece el topónimo Levante como sinónimo de València, y es usado tanto fuera como dentro de la misma València (por ejemplo por un importante equipo de fútbol, por un notable periódico y por multitud de otras empresas privadas). A veces el territorio que abarca Levante no se restringe al País Valenciano: ${ }^{15}$ también incluye Murcia u otros territorios del este peninsular. Joan Fuster califica el topónimo Levante de deformador, y ve en él una intención clara de retirar de la circulación el término valenciano para designar a todo el país, limitándolo a la provincia de València. Para Fuster, cuando alguien habla de Levante para referirse al País Valenciano, sin duda trata "d'escamotejar l'única realitat pròpia dels valencians: l'oculta, l'enterboleix o la nega". ${ }^{16} \mathrm{El}$ Consell Valencià de Cultura, órgano consultivo en materia cultural de les Corts Valencianes, estableció en 1996 la inconveniencia de usar el término Levante para referirse a las tierras valencianas. ${ }^{17}$

Para Josep Vicent Boira la pérdida de valor oficial del concepto de (Reino de) València y la implantación de la división provincial no impidieron que en 1909 todavía continuara existiendo cierta percepción de la valencianidad común, basada en la historia y en la geografía. Como muestra, Tomás Trénor organizó una Exposición Regional Valenciana donde fueron invitadas las tres provincias valencianas vigentes entonces y ahora, pero no las otras provincias limítrofes. ${ }^{18}$ Pocas décadas después, dentro de los círculos valencianistas de la Segunda República, surgirá un nuevo interés por la identidad valenciana y, con este, las primeras propuestas de comarcalización del País Valenciano.

\footnotetext{
15 El término País Valenciano apareció en el siglo xviII, pero solo llegó a usarse ampliamente durante la Segunda República Española (1931-1939), en el tardofranquismo y en la democracia que siguió a este. Hoy sigue siendo empleado por sectores progresistas de la sociedad civil y por algunos partidos políticos de izquierda, mientras que es estigmatizado y vetado por la derecha.

16 Fuster, 1962, p. 118.

${ }^{17}$ http://cvc.gva.es/archivos/40\%20i\%2041.pdf

${ }_{18}$ Boira, 2012b, p. 55-56.
} 


\subsection{Las propuestas de comarcalización durante el siglo $x x$}

Durante la Segunda República nació en València, en especial dentro de los círculos valencianistas, un nuevo interés por la cuestión comarcal. Este proceso imitaba el iniciado en Catalunya, ya que la primera división comarcal moderna de València, la de Felip Mateu i Llopis, se presentó en 1933, solo unos meses después de que el entonces conseller de Governació de la Generalitat de Catalunya Josep Tarradellas firmase la Ponencia para la División Territorial de Catalunya, dirigida por el geógrafo Pau Vila. Un año después Emili Beüt i Berenguer pronunciaba una conferencia en el Cercle d'Actuació Valencianista donde explicaba sus ideas sobre la cuestión comarcal; dicha conferencia constituyó la base de una propuesta de comarcalización que Beüt no llegó a publicar hasta 1970.

Las propuestas de Mateu y Beüt, basadas en autores como Cabanilles y otros anteriores, fueron las primeras del siglo xx que pretendían dividir en unidades comarcales homologables todo el territorio valenciano. Antes se habían hecho otras divisiones de carácter fiscal (quarters del tall de drap, s. xv) o judicial (partidos judiciales, s. xix) con un carácter mucho más administrativo. Las de Mateu y Beüt, sin embargo, partían de la concepción tradicional de la comarca como una unidad natural definida a partir de rasgos físicos, históricos, lingüísticos y culturales (formas de vida y producción).

Las comarcalizaciones propuestas durante la República fueron un referente para las propuestas posteriores, entre las cuales destacará por encima de todas la de Joan Soler i Riber de 1970, que consiguió el apoyo de intelectuales e instituciones públicas y privadas, gracias a la difusión que tuvo en diversas publicaciones, notablemente la Gran Enciclopèdia Catalana y la Gran Enciclopedia de la Región Valenciana. En la actualidad, la división comarcal de Soler es la más conocida, e incluso ha llegado a alcanzar un cierto grado de implantación en la conciencia popular, aunque dicha implantación varía mucho de unas comarcas a otras y, dentro de una misma comarca, de unas localidades a otras. (Vid. Figura 5)

Figura 5. Propuesta de comarcalización de Joan Soler (1970), en la que se inspiraron las DTH

(Demarcaciones Territoriales Homologadas) de $1^{\circ}$ rango (Generalitat Valenciana, 1988)

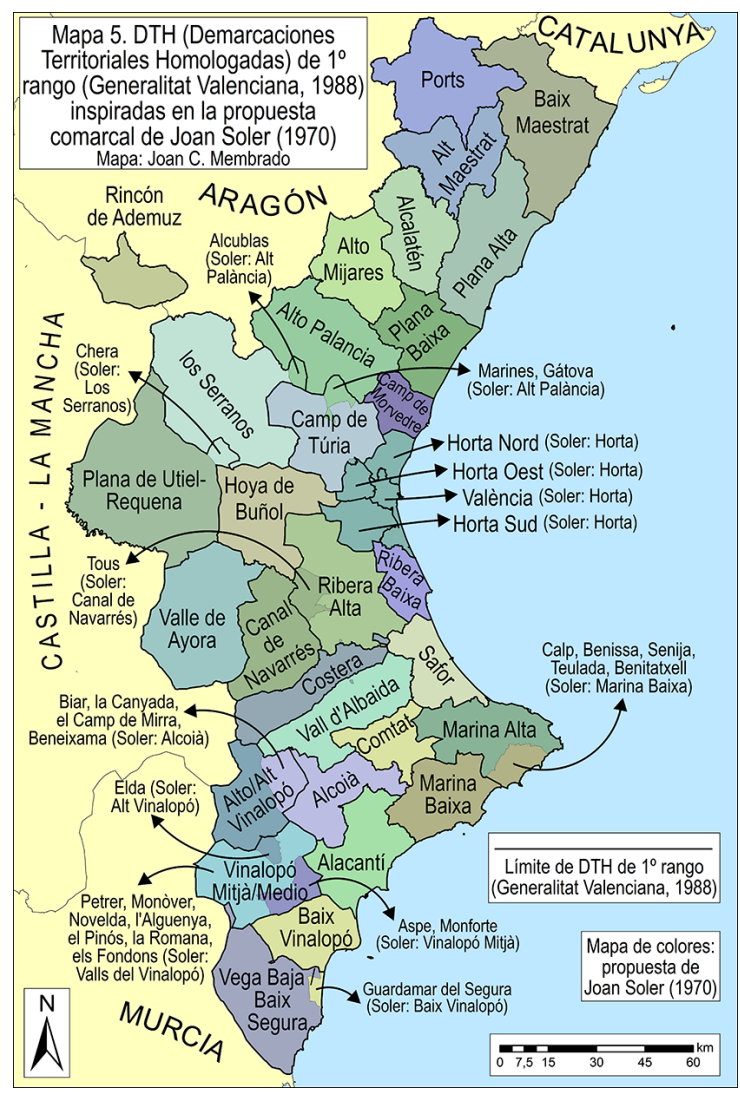


Una de las claves del éxito de la propuesta de Soler fue prevenir posibles reacciones localistas al evitar, siempre que fuera posible, que el nombre de la comarca coincidiera con el de su capital. Para evitar dicha coincidencia Soler buscó un nombre, casi siempre de tipo fisiográfico, que no hiciera referencia a la capital comarcal, acuñando así el término Baix Segura (en lugar de Horta d'Oriola), Baix Vinalopó (y no Camp d'Elx), Alt Palància (no Vall de Sogorb) o Camp de Túria (no Camp de Llíria). Otras veces, Soler recorrió a la recuperación de nombres históricos en desuso, creando así el Camp de Morvedre para referirse a la comarca de Sagunt, l'Alcalatén para la de l'Alcora, el Comtat para la de Cocentaina, y la Safor para la de Gandia. En otras ocasiones, Soler eliminó la cabecera comarcal del nombre de la comarca y la sustituyó, con voluntad integradora, por el segundo centro más importante: así, Requena, Ayora, Enguera y Chiva eran en su propuesta las cabeceras comarcales, respectivamente, de la Plana de Utiel, el Valle de Cofrentes, la Canal de Navarrés y la Hoya de Buñol. Para evitar que un topónimo municipal apareciese en el nombre de la comarca, a veces lo eliminaba: así, l'Horta de València es l'Horta; els Ports de Morella, els Ports; y la Plana de Castelló, la Plana (Alta o Baixa, pero no de Castelló); sin embargo no prescinde del topónimo, aunque podría haberlo hecho, en los casos de la Hoya de Buñol (que podría haber sido simplemente la Hoya) o la Canal de Navarrés (en vez de la Canal). Cuando el peso del centro comarcal era abrumador y, podría decirse, no había más remedio que incluir su nombre en el topónimo comarcal, se optó por adoptar como tal el gentilicio de la capital de la comarca: son los casos de l'Alcoià y l'Alacantí. Hay cuatro grandes comarcas que son subdividas en Alta y Baixa, y una (el Vinalopó) lo es en Alt, Mitjà y Baix, pero mientras que en el Vinalopó, la Ribera y el Maestrat esta distinción responde a criterios de altitud, en los casos de la Plana y la Marina sigue criterios de latitud, incongruentes desde el punto de vista fisiográfico.

Soler confesó que su propuesta seguía el mismo criterio que la Ponència per a la Divisió Territorial de Catalunya de los años 1930. Esta definía unas unidades de vida colectiva cohesionadas a través de les relaciones de vecindad entre los núcleos que las integrasen, más algunas condiciones fisiográficas y la huella inevitable de las demarcaciones históricas. Dichas unidades habían de contar con un centro que polarizara las actividades económicas y ofreciera los servicios indispensables, de forma que la comarca fuera una unidad orgánica y funcional, lo que era indispensable para un buen régimen de administración local. Así pues, a la hora de delimitar una comarca, Soler prima los criterios de operatividad administrativa, que exigen, por un lado, la existencia de un centro importante, y por otro, que la demarcación sea de una extensión territorial mediana, ni muy grande ni muy pequeña, de un tamaño que esté, por así decir, al alcance de las personas, de modo que, además de una demarcación administrativa, la comarca se convierta en un "sentimiento". ${ }^{19}$ Soler no buscaba, en cambio, un equilibrio similar en cuanto a la demografía, de modo que, mientras el tamaño de sus comarcas es más o menos equiparable, las diferencias en cuanto a la población son enormes: el Alt Millars -con poco más de 4.000 habitantes- posee hoy una población unas 300 veces inferior a la de l'Horta. Por otra parte, no en todas las comarcas existe un centro que polarice la actividad comarcal: el caso más extremo es el de la cabecera comarcal del mismo Alt Millars, Cirat, una pequeñísima localidad de unos 250 habitantes que no ejerce la menor función polarizadora ni siquiera sobre sus alrededores más inmediatos.

Según Rosselló, la delimitación comarcal de Soler se basó en mapas de mercados elaborados en una época (la década de 1950) donde todavía era vigente l'economia del carro. ${ }^{20}$ Si tenemos en cuenta el ocaso de los mercados tradicionales y el fuerte desarrollo de la red viaria durante los últimos años, podemos comprender la debilidad de este criterio. Otra crítica a la propuesta soleriana es la subordinación total al criterio lingüístico: el propósito de separar a toda costa las localidades catalanohablantes de las castellanohablantes le lleva a romper la unidad fisiográfica y de relaciones de vecindad de algunas comarcas, especialmente las de la cuenca del Vinalopó, donde crea a partir de Aspe y Monforte una pequeña comarca llamada Vinalopó Mitjà, separada de su entorno comarcal natural (les Valls del Vinalopó), mientras que adscribe a la comarca de Villena (l'Alt Vinalopó) las ciudades castellanohablantes de Salinas y Elda, la última de las cuales queda así separada de la valencianohablante de Petrer, a pesar de que ambas

\footnotetext{
19 Piqueras y Membrado, 1995, p. 344.

20 Rosselló, 1993, p. 45.
} 
conforman un continuo urbano. No es esta, sin embargo, la única área urbana que queda dividida: lo mismo ocurre con las conurbaciones urbano-industriales de la Plana (Castelló, Almassora, Vila-real y Onda), y de Alcoi-Cocentaina-Muro. Finalmente, también se le puede reprochar a Soler que no reconozca unidades de dimensiones relativamente reducidas pero con una personalidad bien definida como la Foia de Castalla, la Vall de Montesa, el Pla de l'Arc o la Valldigna y, en cambio, sí admita comarcas de tamaño similar a estas con menor homogeneidad física, humana y económica, como el Comtat y, sobre todo, el Vinalopó Mitjà de Aspe y Monforte.

Vicenç Rosselló publicó en 1987 (aunque había sido redactada en octubre de 1982 por él mismo, por el también geógrafo J. M. Bernabé y por el economista B. Cabrer) una propuesta basada en comarcas con un mínimo de población (aproximadamente unos 100.000 habitantes), lo que sacrificaba la homogeneidad de su tamaño. Esta propuesta pretendía reducir a un máximo de 12 el número de comarcas, ya que se consideraba que una cifra más alta no sería operativa si, como parecía previsible, se mantenían las actuales provincias. Fue presentada ante una comisión de expertos convocada en 1982 por el primer Consell de la Generalitat Valenciana, con el propósito de determinar una propuesta de división comarcal definitiva, siguiendo así el mandato del artículo 46 del Estatut (artículo 65 tras la reforma de 2006). Más de la mitad de los representantes de la comisión aceptaron la propuesta de las 12 unidades, que, tras una primera rectificación, se convirtieron en 14 y, posteriormente, en 16 comarcas o gobernaciones o demarcaciones que se designarían con el nombre de sus capitales respectivas, acompañadas además de dos distritos metropolitanos: el de València, que abarcaría las demarcaciones del Cap i Casal y de Sagunt, y el de Alacant-Elx.

Figura 6. Propuesta de comarcalización de Rosselló et alii (1982-87), en la que se inspiraron las DTH (Demarcaciones Territoriales Homologadas) de $2^{\circ}$ rango (Generalitat Valenciana, 1988)

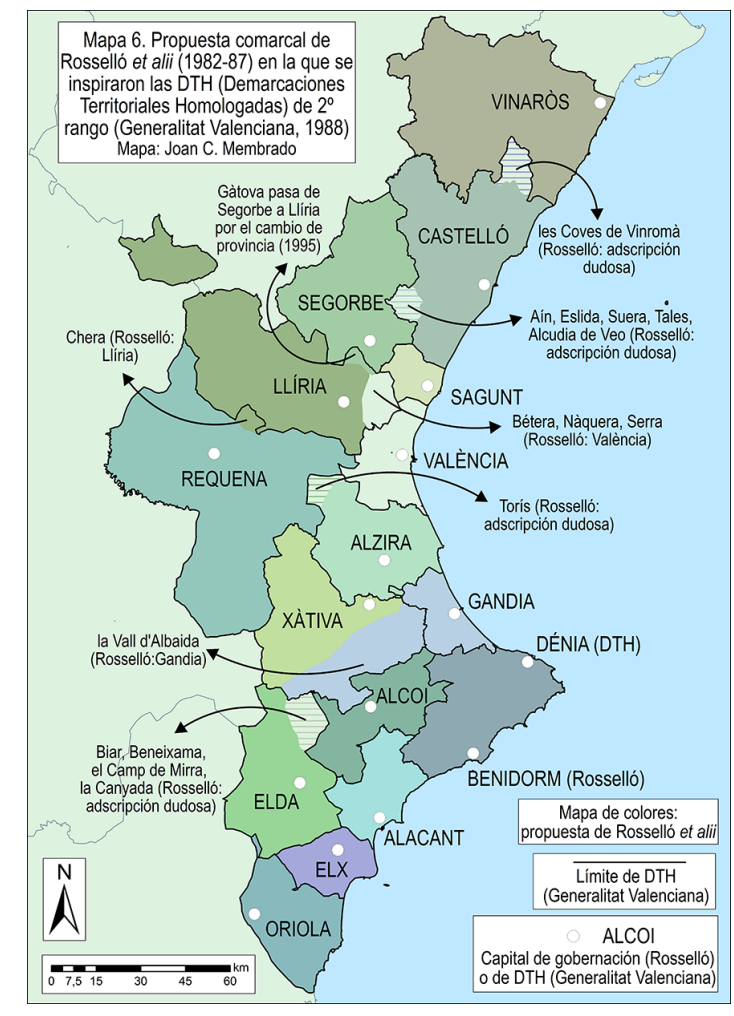

Entre las propuestas de ordenación territorial presentadas hasta aquel momento, esta era la que más coherentemente respondía a una concepción funcional, si bien tenía sus puntos débiles que, en parte, se explican porque sus autores -llevados por una voluntad de realismo político-consideraron que la realidad provincial era, en principio, intocable. El mantenimiento de las estructuras provinciales desaconsejaba, 
según Rosselló, la existencia de más de un nivel de ordenación comarcal, de modo que esta propuesta de 16 gobernaciones resultaba incompatible con una concepción de la comarca como espacio vivido, como la de Soler y sus 32 comarcas. Al mismo tiempo, se castigaba precisamente a las comarcas deprimidas, borrándolas del mapa, con lo que se inutilizaba también la comarca como instrumento para la corrección de los desequilibrios territoriales. El mantenimiento de las actuales provincias también provocaba una distorsión notable en algún caso por lo que respecta al mínimo de población aconsejable. En lugar de proponer una comarca funcional con capital en Sagunt que abarcase toda la cuenca del Palancia (Alto Palancia y Camp de Morvedre), la propuesta postulaba crear dos demarcaciones: una con capital en Sagunt (provincia de València) que, al mismo tiempo, formaba parte del distrito metropolitano de la ciudad de València; y otra con capital en Segorbe (provincia de Castelló), que incluyese también el Alto Mijares, aunque este tiene su verdadero centro en la Plana. Esta demarcación segorbina, con menos de 30.000 habitantes, estaba lejos del umbral mínimo de 100.000 de que partían los autores de la propuesta (Vid. Figura 6).

\section{POLÍTICA TERRITORIAL DE LA GENERALITAT VALENCIANA}

El actual Estatut de Autonomía de València, promulgado en 1982, y reformado en 2006, afirma en su artículo 65 que una ley de Les Corts, que tendrá que aprobarse por mayoría de dos tercios, podrá determinar la división comarcal, y que las comarcas son circunscripciones administrativas de la Generalitat y entidades locales determinadas por la agrupación de municipios para la prestación de servicios y la gestión de asuntos comunes. ${ }^{21}$ Sin embargo, actualmente València sigue sin contar con una comarcalización oficial, y la voluntad de poner alguna en funcionamiento parece que es nula.

En la historia de la actuación de las instituciones autonómicas valencianas en esta cuestión pueden distinguirse cuatro momentos. Durante el primero, entre 1982 y 1987, los políticos parecen tener un verdadero interés en sacar adelante la comarcalización -respondiendo al espíritu del Estatut-y creen que es la Generalitat quien debe asumir la iniciativa en todo el proceso. En 1979 Manuel Girona, entonces presidente de la Diputación de València, se presentaba en unas conversaciones sobre comarcalización como el último presidente de la Diputación, institución que entonces empezaba a ceder sus competencias a una Generalitat incipiente. ${ }^{22}$ Los políticos valencianos hacen solemnes declaraciones en las que identifican autonomía con comarcalización, y afirman que comarcalizar ayuda a la integración y recomposición natural de las tierras valencianas. El Consell de la Generalitat convoca una comisión de expertos en comarcalización, que se reúne en 1982 y en 1984; en 1985 se crea la Conselleria de Administración Pública con Vicent Soler al frente, quien posee una decidida voluntad de impulsar la comarcalización. Durante este periodo se produjo la única experiencia ambiciosa de consolidación de un ente territorial de tamaño mediano entre la Generalitat Valenciana y los municipios, sin pasar por la provincia: el Consell Metropolità de l'Horta. Este se creó por la ley de 31 de diciembre de 1986 y pretendía elaborar en 7 meses unas normas de coordinación metropolitana. Dichas normas metropolitanas, cuyo ámbito geográfico era la ciudad de València y otros 43 municipios de l'Horta, fueron, según Burriel (2009), "el primer instrumento de planificación territorial de la Comunidad Valenciana y, lo que resulta aún más llamativo, el único que hasta ahora ha estado vigente". Estas normas, aprobadas por el Consell de la Generalitat Valenciana en verano de 1988, "buscaban la coordinación de los planes municipales de ordenación urbana que habían empezado a plantear los nuevos ayuntamientos democráticos de la comarca". Todos los municipios del Consell Metropolità de l'Horta "estaban obligados a respetar estas normas al redactar sus nuevos planes de ordenación urbana y a modificar el planeamiento vigente en lo que se opusiera a ellas en un plazo de 18 meses".

A pesar de los aparentes avances, hubo fuertes presiones que impidieron continuar con el proceso de comarcalización, y en 1987 su principal valedor, Vicent Soler, fue sustituido por Joaquín Azagra. El exconseller Soler ha declarado posteriormente que dentro de su partido había una gran oposición interna

\footnotetext{
${ }^{21}$ http://www.idpbarcelona.net/docs/normativa/ccaa/normativa/lleis/cvalenciana/estatut.pdf

22 Rosselló, 1993, p. 41.
} 
a las comarcas, especialmente desde Alacant, donde temían perder la capitalidad provincial. ${ }^{23}$ Con Azagra se inicia el segundo momento de la actuación de la Generalitat, caracterizada porque la cuestión comarcal se relega a un segundo o tercer plano y por la idea de que la comarcalización se ha de construir desde abajo, es decir, que deben ser los propios municipios quienes deben tener la iniciativa de mancomunarse en unidades más o menos comarcales, lo que supuestamente ahorraría a la Generalitat el coste político que podría llegar a suponerle una comarcalización hecha por decreto.

No obstante, durante el período de Azagra (1987-1989), la Dirección General de Administración Local publicó una comarcalización de referencia que recogía el modelo de ordenación territorial que deseaba la Generalitat: las llamadas Demarcaciones Territoriales Homologadas (DTH), de 1988. Las DTH establecían distintos niveles de división territorial, donde las unidades inferiores debían ajustarse a los límites de las superiores: el primer nivel (DTH de primer rango) dividía València en las mismas comarcas que Joan Soler, salvo algunos retoques, el más importante de los cuales era la redefinición del Vinalopó Mitjà como una comarca que abarcaba toda la cuenca media del Vinalopó, desde Elda hasta Aspe, sin separar los pueblos valencianoparlantes de los castellanófonos. El segundo nivel (DTH de $2^{\circ}$ rango) reproducía la propuesta de las 16 gobernaciones de Rosselló, Cabrer i Bernabé, con la única modificación de que la Vall d'Albaida pasaba de la demarcación de Gandia a la de Xàtiva. El tercer nivel coincidía con las tres provincias actuales (figura 7 ).

Figura 7. Demarcaciones Territoriales Homologadas (DTH) propuestas por la Generalitat Valenciana (1988).

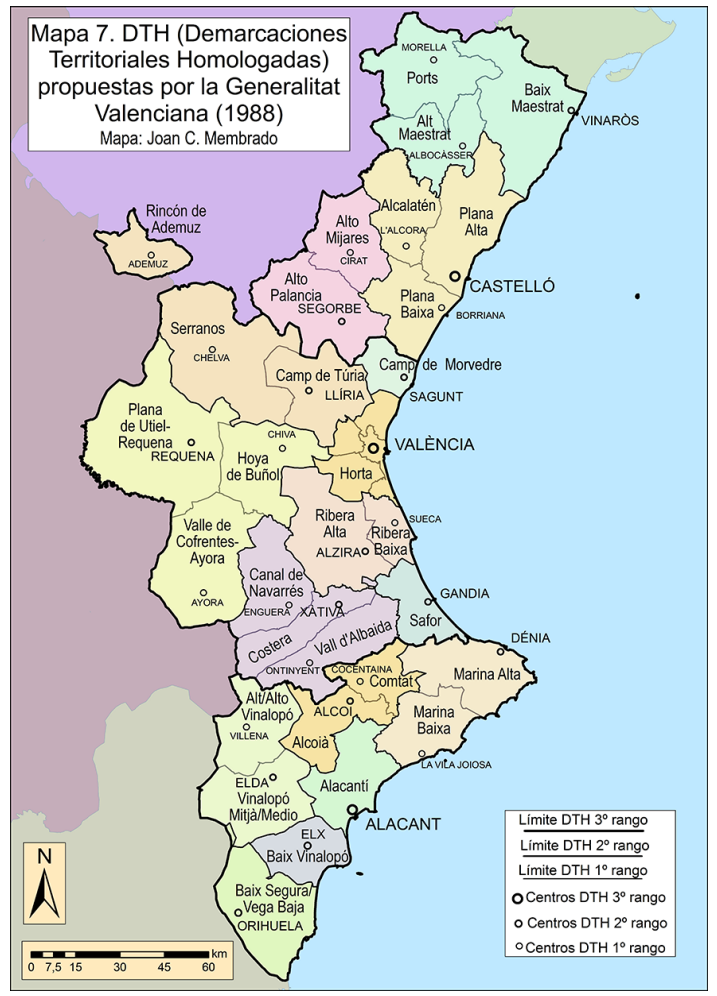

El papel de las DTH, según la Conselleria de Administración Pública, consistía en coordinar en una única división territorial las áreas de actuación funcional, caracterizadas hasta entonces por la diversidad e incluso por la contradicción entre las diferentes conselleries, para así avanzar homogéneamente en la tarea común de lograr una división comarcal. Partiendo de las DTH de $2^{\circ}$ rango se trazaron los límites de las áreas sanitarias de València (figura 8), de las oficinas PROP de la Generalitat, ${ }^{24}$ de los partidos

\footnotetext{
${ }^{23}$ http://www.levante-emv.com/comarcas/2012/05/27/treinta-anos-comarcas/908257.html

${ }^{24}$ La red pública de oficinas PROP, descentralizadas por todo el territorio valenciano, facilita información sobre trámites o procedimientos de la Generalitat Valenciana y sobre empleo público.
} 
judiciales valencianos (figura 9), del mapa escolar, del mapa agrario, etc. Por otra parte, las DTH (de primer rango) servían como referencia para el proceso de construcción desde abajo de las comarcas a partir de las mancomunidades: así, se pretendía incentivar particularmente aquellas mancomunidades de interés comarcal que se aproximasen al modelo de las DTH.

Figura 8. Mapa sanitario de València, ajustado aproximadamente a las DTH de $2^{\circ}$ rango.

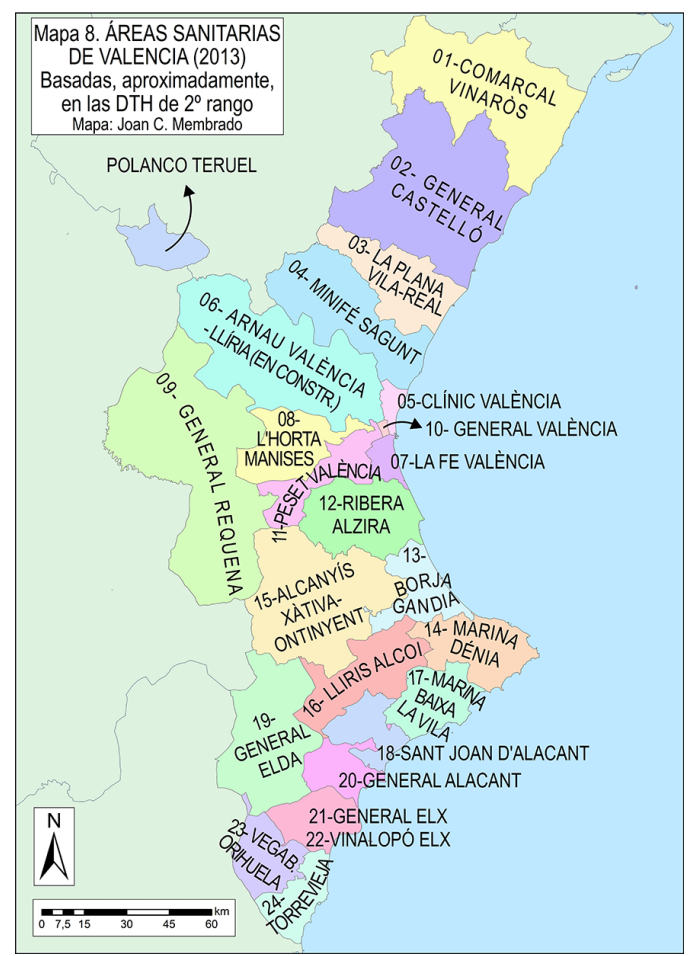

Figura 9. Mapa judicial de València, ajustado aproximadamente a las DTH de $2^{\circ}$ rango.

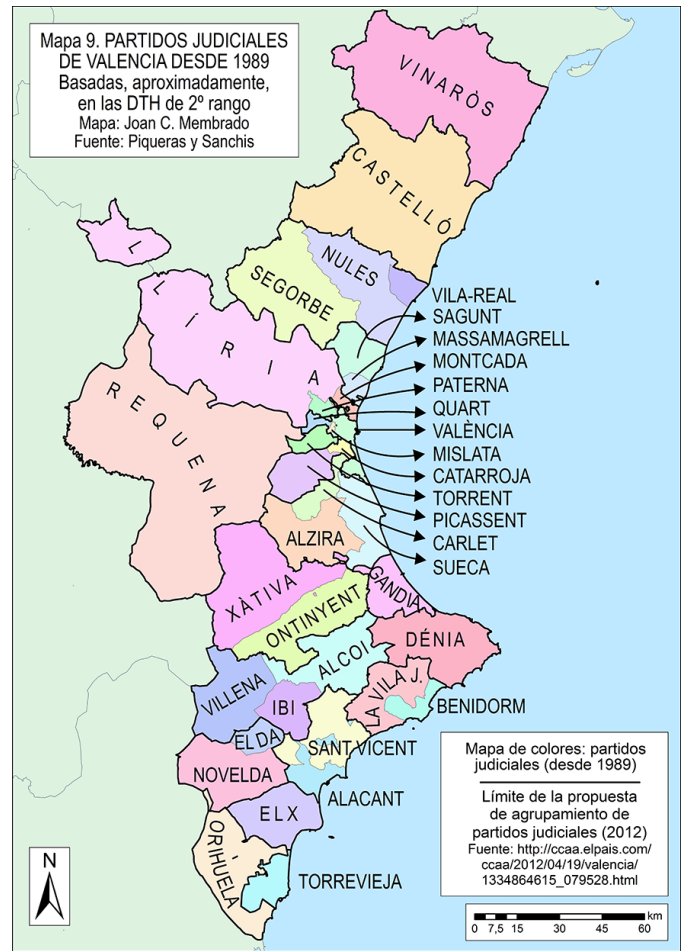


Sin embargo, la Ley de gobierno local y organización territorial de la Comunitat Valenciana (1988) que recogía las iniciativas de apoyo a las mancomunidades, quedó paralizada durante el mandato del conseller Emèrit Bono (1989-1993) con la supresión en 1993 de la Dirección General de Administración Local, lo que congeló también la vía de las mancomunidades. En la actualidad hay 60 mancomunidades en València, ${ }^{25}$ con unas dimensiones y un número y escala de servicios mancomunados muy heterogéneos. Los servicios más habituales que ofrecen las mancomunidades son los de asistencia social, recogida y tratamiento de basura, abastecimiento y depuración de aguas o promoción turística, que son competencias similares a las de las comarcas catalanas o aragonesas, si bien allí se llevan a cabo a partir de las comarcas oficiales y en València solo se ofrecen en municipios mancomunados voluntariamente. El hecho que la Generalitat finalmente congelase la ley que incentivaba las mancomunidades ajustadas a los límites comarcales (DTH de primer rango) ha supuesto que la mayoría de las 60 mancomunidades valencianas no se ajusten a dichos límites.

Durante los últimos años de gobierno socialista en la Generalitat se inició una tercera etapa dentro de este largo proceso de progresivo desinterés por la reforma de la ordenación territorial valenciana por parte del gobierno autonómico valenciano, que decidió aplazar sine die todo el problema. ${ }^{26}$ Es más, las competencias del único organismo supramunicipal creado durante este tiempo, el Consell Metropolità de l'Horta (CMH), fueron reducidas por una ley de la Generalitat de 1995, poco antes de la marcha de Joan Lerma como presidente de la Generalitat. Poco después, en 1999, Eduardo Zaplana suprimió definitivamente dicho Consell. ${ }^{27}$ Para asumir sus competencias aprobó la más comedida Ley 2/2001 de creación y gestión de áreas metropolitanas en la Comunitat Valenciana,$^{28}$ a partir de la cual se crearon dos nuevas entidades metropolitanas: la Entidad Metropolitana para el Tratamiento de Residuos (Emtre) y la Entidad Metropolitana de Servicios Hidráulicos (Emshi), cuya gestión económica -en este segundo caso- ha resultado desastrosa. ${ }^{29}$

Por otro lado, la Generalitat siguió tomando como referencia las mismas demarcaciones territoriales homologadas (DTH) para la descentralización administrativa de los servicios que ofrecía (sanidad, justicia, enseñanza, agricultura, oficinas PROP...). Pero solo como referencia: las comarcas o DTH seguían sin contar con cobertura legal para convertirse en órganos políticos o administrativos con competencias reconocidas, como lo son los consejos comarcales de Catalunya o de Aragón. Además, aunque es cierto que se trazaron los partidos judiciales, las demarcaciones sanitarias o el mapa escolar tomando como base esas comarcas no oficiales o, como las llama el exconseller Vicent Soler, comarcas fantasma, el mismo Soler afirma que "al no haber un consenso sobre el mapa territorial, cada servicio tiene su propio mapa y eso acaba dando como resultado una selva de mapas que deberían ordenarse y racionalizarse" ${ }^{30}$ Por otro lado, el enorme aumento demográfico de las comarcas de la Marina y la Vega Baja obligó a la Generalitat a duplicar sus servicios, desdoblando de hecho ambas DTH de $2^{\circ}$ rango: la de la Marina funciona realmente con dos cabeceras comarcales (una en Benidorm/la Vila Joiosa y otra en Dénia, adaptándose a sus respectivas DTH de primer rango), y la Vega Baja con otras dos (Orihuela y Torrevieja, que hoy son la quinta y la sexta ciudad valenciana, respectivamente).

La reforma del Estatut de 2006, pactada por el PP y el PSOE, introduce algunos cambios sutiles que socavan la identidad valenciana: la Generalitat Valenciana se convierte ahora en la Generalitat, y les Corts Valencianes en les Corts, eliminando así el gentilicio común, para evitar susceptibilidades en las provincias del norte y del sur. El topónimo Comunitat Valenciana, en catalán/valenciano, se establece como el único

\footnotetext{
${ }^{25}$ http://www.gva.es/va/inicio/otras_administraciones/lav_entidades_locales/lav_el_todas_entidades/lav_el_todas_entidades_manc

${ }^{26}$ Como paradigma del desinterés por comarcalizar, en 1993 se nombraron delegados de la Generalitat en las tres provincias, donde ya hay delegados del gobierno y presidentes de diputación, con lo cual se estaban duplicando o triplicando los servicios y la burocracia (Rosselló, 1993, p. 47). Un síntoma del refuerzo de la identidad provincial en este periodo es el citado por Rosselló al referirse a la inauguración de un monumento a la dona valenciana en la avenida de Blasco Ibáñez del Cap i Casal, que consiste nada menos que en tres mujeres vestidas de labradoras, una por cada provincia (p. 40)

${ }^{27}$ http://elpais.com/diario/1999/12/07/cvalenciana/944597882 850215.html

8 Bassols, 2004, p. 566-67.

29 Emshi es propietaria de Emarsa (Empresa Metropolitana de Aguas Residuales de Valencia SA), el saqueo de cuyas arcas supuso un agujero de al menos 17 millones de euros: http://politica.elpais.com/politica/2012/01/15/actualidad/1326649186 916777.html

${ }^{30}$ http://www.levante-emv.com/comarcas/2012/05/27/treinta-anos-comarcas/908257.html
} 
oficialmente reconocido por el Estatut para dar nombre a la comunidad autónoma, que también reconoce País Valenciano y Reino de Valencia en su preámbulo. A diferencia de lo que ocurrió con la Generalitat y con les Corts, el gentilicio Valenciana no se eliminó en el topónimo de la comunidad, pero en 2010 la Generalitat llevó a cabo una campaña publicitaria para promover determinados valores positivos propios del territorio valenciano con el nombre Som Comunitat, ${ }^{31}$ donde se suprime el gentilicio con intenciones supuestamente integradoras, evitando de nuevo herir susceptibilidades o crear malentendidos en la provincias de Castelló y Alacant. La división provincial está tan profundamente arraigada en la sociedad valenciana que la mayoría de políticos y medios de comunicación, tanto conservadores como progresistas, utilizan el término la Comunitat o nuestra Comunitat con preferencia respecto a Comunitat Valenciana.

El nuevo Estatut reformado en 2006, en su artículo 64.1, establece la obligación de aprobar una ley de régimen local de la Comunitat Valenciana, que fue aprobada en junio de 2010 (Ley 8/2010). En su artículo 1, sobre entidades locales, dice que "la Comunitat Valenciana se organiza en municipios, comarcas y provincias a las que se garantiza la autonomía para la gestión de sus respectivos intereses". Se refiere, como decía Soler, a unas comarcas fantasma, ya que primero habría que oficializarlas para que fuera posible garantizarles algo. En su artículo 53, sobre Concepto y división comarcal, sin aportar nada nuevo a lo que ya dice el Estatut en su artículo 65, insiste en que les Corts pueden determinar la división comarcal mediante ley aprobada por mayoría de 2/3.

A pesar de la no-oficialidad de las comarcas, hay que reconocer que estas, por su tamaño intermedio entre la provincia y el municipio, que las acerca más al ciudadano, tienen cierta incidencia territorial, ya que, por ejemplo, los principales partidos políticos de València, incluyendo el PP, se organizan por comarcas (la mayoría coincidentes con las de Joan Soler o DTH de primer rango), las cuales organizan sus respectivos congresos. El Institut Valencià d'Estadística, dependiente de la Generalitat, también distribuye la información por comarcas (DTH de primer rango). Fuera del ámbito político, los principales periódicos valencianos tienen secciones y/o ediciones comarcales. Además, el nombre de las comarcas (en unos casos más que en otros) está muy presente en la denominación de muchas empresas tanto públicas (hospitales, ${ }^{32}$ centros de enseñanza...) como privadas (áreas de servicio de autopista, ${ }^{33}$ empresas industriales, agrícolas, de servicios).

En el artículo 2 de la ley de régimen local de la Comunitat Valenciana se afirma que también son entidades locales las entidades locales menores, áreas metropolitanas y mancomunidades de municipios. En su artículo 74 , sobre áreas metropolitanas, menciona que estas son entes integrados por municipios de grandes áreas urbanas entre los cuales haya "vínculos urbanísticos, económicos y sociales que hagan necesaria la planificación conjunta y la gestión coordinada de determinadas obras y servicios" y que tendrán "personalidad jurídica propia y plena capacidad para el ejercicio de sus competencias". En su artículo 91, sobre mancomunidades, se refiere a estas como "asociaciones voluntarias de municipios que se constituyen para gestionar y/o ejecutar planes, realizar proyectos y obras o prestar servicios de su competencia". En su artículo 52, sobre coordinación de la Generalitat con las Diputaciones Provinciales, se aprecia cuál es el modelo de vertebración territorial que propone el partido gobernante en València. Establece que para institucionalizar la relación entre Generalitat y diputaciones y "promover la cohesión territorial en la Comunitat Valenciana se celebrará con periodicidad anual una cumbre de cohesión territorial entre la Generalitat y las diputaciones provinciales". Este es un modelo que desde el punto de vista identitario ha fracasado estrepitosamente, como muestran las encuestas del CIS a las que nos hemos referido en la introducción, y que tras más de 30 años de gobierno autónomo no ha hecho sino entorpecer la consolidación de la identidad valenciana.

Los gobiernos del PSOE y del PP no han sido capaces de dotar a los valencianos, como afirma Boira, "de una conciencia y de una capacidad de acción colectiva, rica, plural y enérgica". Si la hubiese tenido,

\footnotetext{
31 http://www.gva.es/contenidos/publicados/Manual_sOM_ok.pdf

32 Hospital de la Plana (Vila-real), de l'Horta (Manises), de la Ribera (Alzira), de la Marina (Dénia), de la Marina Baixa (la Vila Joiosa), del Vinalopó (Elx) o de la Vega Baja (Orihuela).

33 Área de servicio de la Plana (Borriana), de la Safor (Xeresa) o de la Marina (la Vila Joiosa).
} 
asegura este geógrafo, "no se habría llegado a este grado de corrupción, de despilfarro, de maltrato al propio país y a los propios ciudadanos" ${ }^{34}$. Con esta crisis entramos en el cuarto momento por lo que respecta a la política territorial valenciana, no ya de desinterés ni apatía por las comarcas, sino de supresión o adelgazamiento de cualquier ente territorial de rango inferior a las comunidades autónomas, salvo las provincias. Las mancomunidades corren peligro de perder su financiación debido a los recortes $;{ }^{35}$ también los pequeños municipios podrían entrar en un proceso de fusión para alcanzar un umbral mínimo de población que los hiciera viables ${ }^{36}$ y se está planteando la reforma de los partidos judiciales, para reducir su número (figura 9) ${ }^{37}$ Por otro lado, las mismas comunidades autónomas han sido ampliamente cuestionadas por determinados sectores políticos y por sus medios afines. Las diputaciones provinciales son las que de momento parecen salir mejor paradas, ya que desde los gobiernos de España y de València y los medios de comunicación que les son afines no se cuestionan sus competencias, e incluso podrían asumir las que aún son propias de las mancomunidades si estas últimas se suprimen. Solo una parte de los partidos progresistas aboga por la eliminación o, al menos, la racionalización, de las diputaciones provinciales. ${ }^{38}$

\section{CONCLUSIÓN}

El nuevo modelo de estado autonómico descentralizado que surgió de la Constitución Española de 1978 no afectó ni a los municipios ni a las provincias, que continuaron con la misma configuración que había diseñado Javier de Burgos en 1833. La llegada de la democracia aprovechó las estructuras municipales y provinciales ya existentes para el desarrollo de la nueva forma de organización descentralizada - las comunidades autónomas -, sin ni siquiera reflexionar sobre si la estructura provincial era compatible con la autonómica. El Estatut valenciano (1982), a diferencia de la Constitución (1978), sí que previó diferentes fórmulas organizativas (comarcas, áreas metropolitanas, agrupaciones de comarcas) que podían ser utilizadas por la Generalitat Valenciana para llevar a cabo una nueva división territorial más adecuada a sus necesidades y a la realidad social del País Valenciano.

A nuestro entender, en el caso que se llevase adelante una comarcalización administrativa de València, como se ha hecho ya en Aragón o en Catalunya, lo más razonable sería tomar como puntos de referencia las divisiones sanitaria y judicial (mapas 8 y 9). Es decir, diseñar una comarcalización asimétrica, en función de la población, a diferencia de la de Catalunya y Aragón, donde se ha buscado un equilibrio en el tamaño de los territorios. Tanto el mapa judicial como el sanitario resultan especialmente significativos para hacernos una idea de los tres esquemas de ocupación del territorio en que se divide el País Valenciano. Por un lado, las enormes demarcaciones del norte y del interior, donde la población y los servicios se concentran en los llanos costeros (Vinaròs, Castelló, Sagunt, Llíria, València) y donde las poco pobladas tierras interiores carecen de auténticos centros comarcales (con la excepción de Requena). Por otro lado, el segundo modelo territorial, mucho más equilibrado respecto a la relación población/extensión, aparece desde la Ribera del Xúquer hasta la Vega Baja, y se configura a partir de demarcaciones densamente pobladas que cuentan con auténticas cabeceras comarcales (Alzira, Xàtiva, Gandia, Dénia, Benidorm, Ontinyent, Alcoi, Villena, Elda, Orihuela...). Y, finalmente, la superpoblada área metropolitana de València, dividida en demarcaciones de escaso tamaño que, sin embargo, dan servicio a muchísima población. Esta última demarcación debería dar lugar a un ente metropolitano, al estilo del extinto Consell Metropolità de l'Horta, para coordinar los planes municipales de ordenación urbana de cada uno de los más de 50 municipios que lo compondrían. Y lo mismo valdría para el área urbana de Alacant-Elx, que ya supera los 750.000 habitantes, y que aparentemente sería más fácil de gestionar al abarcar muchos menos municipios que l'Horta.

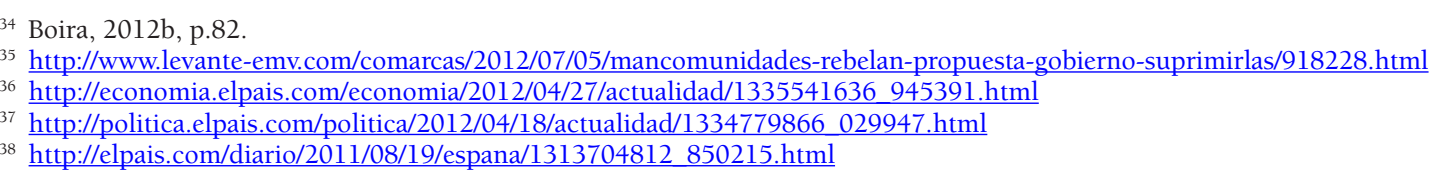


Sin embargo, las posibilidades que brinda el Estatut para crear una nueva organización territorial no han sido apenas aprovechadas. En efecto: el impulso comarcalizador ha sido escaso, y cuando ha existido, o bien ha fracasado, o ha sido abandonado o llevado a la mínima expresión.

Al principio del gobierno socialista de Joan Lerma en la Generalitat Valenciana hubo algunos intentos de sacar adelante una ley de comarcalización para intentar corregir los desequilibrios territoriales y, a la vez, para fomentar unas unidades administrativas -las comarcas- que permitiesen vertebrar mejor el territorio valenciano y reforzar su identidad, después de casi 200 años de fragmentación y erosión de la identidad común a causa de las provincias. En 1986 se llegó a crear el único ente territorial oficial de tamaño mediano entre la provincia y el municipio: el Consell Metropolità de l'Horta (CMH). Pero a partir de 1987 la Generalitat empezó a perder el interés por oficializar las comarcas y optó por favorecer la creación voluntaria de mancomunidades de municipios de interés comarcal. Se crearon así algunas mancomunidades cuyos límites coincidían con los de las comarcas de Soler (DTH de primer rango). Pero en 1993 también se paralizó el apoyo a las mancomunidades de interés comarcal y además las competencias del CMH fueron reducidas por una ley de 1995, poco antes de la marcha de Lerma. Preguntado sobre el fracaso de la vertebración territorial valenciana, el expresidente valenciano acabaría declarando con sorna que los invertebrados también podían ser felices. ${ }^{39}$

En 1995 empezó el gobierno popular en la Generalitat, al principio en coalición con Unió Valenciana. El PP valenciano adoptó una parte de los postulados ideológicos de UV para convertirse en la nueva referencia regionalista valenciana. Ambos partidos partían de las mismas premisas provincialistas, que concebían el Reino de València como una especie de federación de tres subunidades: Alacant, Castelló y València, con personalidad propia que había que respetar para evitar cualquier centralismo de València (provincia). ${ }^{40}$ En 1999 Zaplana suprimió el $\mathrm{CMH}^{41}$ y su interés por fomentar la comarca seguía siendo nulo.

Con los gobiernos populares se reforzó todavía más la identidad provincial. La reforma del Estatut de 2006 eliminó el gentilicio valenciana de Generalitat y valencianes de les Corts y se sólo se conservó en el topónimo Comunitat Valenciana, aunque la mayoría de políticos y medios de comunicación tienden a sustituirlo por la Comunitat o nuestra Comunitat. La Generalitat popular propone vertebrar el territorio valenciano a partir de la suma de las tres provincias, aunque los resultados del CIS muestran el fracaso de esta política.

Aunque el Estatut contempla la creación de las comarcas, tras 30 años de vigencia, estas están más olvidadas que nunca. Si en tiempos de bonanza la indiferencia hacia ellas era remarcable desde la Generalitat, ahora que corren tiempos de recortes es previsible que estas sigan siendo ignoradas, aún más si cabe, por los actuales dirigentes políticos. Entre las diversas reformas de la organización territorial estatal que pretenden adelgazar la administración, el gobierno de España ha propuesto la fusión de municipios, la supresión de las mancomunidades y la reducción del número de partidos judiciales. Por otro lado, la reforma o supresión de las diputaciones no es un tema prioritario, a pesar de que lo han pedido algunos dirigentes de la oposición y los grandes empresarios valencianos; antes al contrario, se prevé que las diputaciones salgan reforzadas, al asumir las competencias que perderían las mancomunidades si estas son suprimidas. Desde Madrid, incluso, algunos dirigentes conservadores y sus medios de comunicación afines han llegado a plantear la supresión de las mismas comunidades autónomas. Entre los mismos valencianos, el número de personas que prefiere un estado sin autonomías ha pasado del 9\% en 2002 al 23\% en 2010. ${ }^{42}$ Esta opción - la desaparición de las autonomías - no es la opinión mayoritaria, sin embargo, ni en el gobierno de España ni en el valenciano, que se dicen contrarios - al menos por ahora - a la devolución de competencias por parte de las autonomías.

\footnotetext{
39 http://www.levante-emv.com/opinion/2010/12/03/amistad-camps-rua/762458.html;

http://www.lasprovincias.es/v/20110306/valencia/posibilidad-historica-valencia-hacerse-20110306.html

40 Flor, 2011, p. 281.

41 http://elpais.com/diario/1999/12/07/cvalenciana/944597882 850215.html

42 Boira, 2012b, p.85, citando datos de Rafa Castelló.
} 


\section{BIBLIOGRAFÍA}

BASSOLS, M. (2004): La Administración Pública de las Comunidades Autónomas. Instituto Nacional de Administración Pública, Madrid.

BEÜT, E. (1970): Les Comarques Valencianes. Conferencia en Lo Rat Penat, València.

BOIRA, J. V. (2012): Valencia, la tormenta perfecta. RBA, Barcelona.

BURRIEL, E. (2009): "La planificación territorial en la Comunidad Valenciana (1986-2009)". Scripta Nova. Revista Electrónica de Geografía y Ciencias Sociales, vol. XIII, nº 306. $<$ http://www.ub.edu/geocrit/sn/sn-306.htm> [Consulta: 20/12/2012].

CARRERAS Y CANDI, F. (1922): Geografía General del Reino de Valencia, Alberto Martín, Barcelona, 4 vol.

CEBREIRO, J. I. (2012): Los orígenes de la división provincial en España, Instituto Nacional de Administración Pública, Madrid.

FLOR, V. (2011): Noves glòries a Espanya. Anticatalanisme i identitat valenciana. Afers, Catarroja.

FORCADELL, C. y ROMEO, M. C. (eds.) (2006): Provincia y nación. Los territorios del liberalismo. Institución "Fernando el Católico", Zaragoza.

FUSTER, J. (1962): Nosaltres els Valencians. Edicions 62, Barcelona.

GIL OLCINA, A. (1990): "Reformismo ilustrado, colonización interior y restablecimiento del fuero alfonsino", en Agricultura y sociedad, 56, pp. 79-112.

MATEU, F. (1933): “Les comarques valencianes”, El País Valencià, pp. 92-112. L’Estel, València.

MEMBRADO, J. C. (1997): "Lordenació territorial del País Valencià: evolució i perspectives actuals. El cas del Baix Vinalopó". La Rella, 11, pp. 65-94. Institut d'Estudis del Baix Vinalopó, Elx.

MESTRE, J. y SABATÉ, F. (1998): Atles de la «Reconquesta». La frontera peninsular entre els segles VIII i XV, Edicions 62, Barcelona.

MIRA, J. F. (1997): Sobre la nació dels valencians. 3 i 4, València.

MUÑOZ, M. R. (1986): "Aproximació a una divisió comarcal a través del Tall de Drap (1404)", actas del X Col-loqui General de la Societat d’Onomàstica i Toponímia, pp. 530-534, València.

PIQUERAS, J. y SANCHIS, C. (1992): L’organització històrica del territori valencià. Generalitat Valenciana, València.

PIQUERAS, J. y MEMBRADO, J. C. (1995): "La política territorial de la Generalitat Valenciana. La comarcalització pendent", Cuadernos de Geografía, 58, pp. 337-364. Departament de Geografia. Universitat de València.

ROSSELLÓ, V. M. (1980): "Les comarques valencianes: un enfocament geogràfic", Taula redona sobre la comarcalització al País Valencià, pp. 39-48. Diputació de València.

ROSSELLÓ, V. M. (1987): "La divisió territorial del País Valencià", Revista de Catalunya, 4, pp. 40-60. Fundació Revista de Catalunya, Barcelona.

ROSSELLÓ, V. M. (1993): "La divisió territorial del País Valencià”, La Rella, 9, pp. 39-48. Institut d’Estudis Comarcals del Baix Vinalopó, Elx.

SALOM, J. (1995): "La política territorial de la Comunidad Valenciana", Cuadernos de Geografía, 58, pp. 209-220. Departament de Geografia. Universitat de València.

SOLER, J. (1970): "La divisió comarcal de País Valencià", L'estructura econòmica del País Valencià, II, pp. 7-31. L'Estel, València.

SOLER, J. (1978): "Problemes comarcals, encara", Serra d'Or, pp. 811-813. Barcelona. 